\title{
The Influence of Antenatal Corticosteroids on Hypoglycemia in Newborn Rats with Intrauterine Growth Retardation
}

\author{
ROBERT L. MANNIILLO(") ANTHONY J. ADAMS, ANI) PHILIP M. FARRELL \\ N'onatal and P'diatric Me'dicine'Branch, National Institute of (Wild He'alth and Human De'velopme'nt, National \\ Institutes of Health. Bethesda, Maryland, USA
}

\begin{abstract}
Summary
This study examines the effect of maternally injected glucocorticoid on the pattern of hypoglycemia exhibited by rat pups with intrauterine growth retardation (IUGR). The majority of surgical procedures designed to produce small-for-gestational age (SGA) newborns for biochemical studies were carried out on days 18 and 19 of gestation because of favorable yields of pups with IUGR at those operative days. At birth, normal controls showed a mean $\pm S E$ plasma glucose value of $63 \pm 2 \mathrm{mg} / \mathrm{dl}$; mean glucose for the group with IUGR was significantly lower at $43 \pm 2 \mathrm{mg} / \mathrm{dl}$. There was a further decrease in the plasma glucose concentration of pups with IUGR at $2-4$ hr of age, whereas values in the control littermates did not fall during this interval. Through the first 2 hr of neonatal life, $46 \%$ of the pups with IUGR exhibited plasma glucose values less than $40 \mathrm{mg} / \mathrm{dl}$, whereas only $18 \%$ of the control littermates manifested hypoglycemia. During the 2-4-hr interval, the incidence of hypoglycemia in animals with IUGR increased to $91 \%$; however, the incidence in controls remained at $18 \%$ from $2-4$ hr and fell to $4 \%$ at 4-6 hr of age. At birth, the pups with IUGR had a lower mean liver weight compared to their control littermates, but glycogen concentration of liver was similar to the control mean \pm SE of $25.7 \pm 1.8$ (IUGR $=22.2 \pm 1.3 \mathrm{mg} / \mathrm{g}$ wet weight). Total hepatic glycogen stores, however, were markedly lower in dysmature rat pups (IUGR $=2.96 \pm 0.17 \mathrm{mg}$; control $=7.23 \pm$ $0.43 \mathrm{mg}$ ). Concentrations of plasma glucose at birth of individual control and IUGR animals were found to correlate significantly $(r=0.64, p<0.001)$ with total liver glycogen content.

The decline in plasma glucose values in pups with IUGR was not present in animals whose dams received glucocorticoid injection 24 and $48 \mathrm{hr}$ before delivery. At $4-6 \mathrm{hr}$ of age, for instance, the mean plasma glucose concentration in the corticoid-freated IUGR group (70.1 $\pm 6.9 \mathrm{mg} / \mathrm{dl}$ ) approximated that of the control group. Instead of the $91 \%$ incidence of hypoglycemia noted in the nontreated dysmature pups, an incidence of $55 \%$ was found at 2-4 hr of age in offspring of mothers given glucocorticoid. At 4-6 hr, the treated group showed an incidence of $18 \%$ compared to a $67 \%$ figure in the nontreated IUGR animals. The concentration of liver glycogen in these animals also differed in that the treated IUG $\dot{R}$ pups showed significantly higher values $(26.9 \pm 1.7 \mathrm{mg} / \mathrm{g}$ wet weight, mean $\pm \mathrm{SE}$ ) than nontreated progeny. It is concluded that antenatally administered corticosteroids influence the development of neonatal hypoglycemia in the dysmature rat pup and that the major effect is not at birth, but during the $2-4$-hr period of neonatal life.
\end{abstract}

\section{Speculation}

These data indicate that hypoglycemia may be prevented by antenatally administered steroids in an animal model of the SG $\boldsymbol{A}$ infant and raise the possibility of prenatal intervention in susceptible fetuses. The protective mechanism that manifests itself in early neonatal life may be attributable to better utilization of gluconeogenic substrates and induction of hey enzymes in developing liver.

Poor fetal growth may result from maternal factors such as toxemia of pregnancy. fetal factors such as chromosomat aberrations. and first trimester viral infections and other unknown causalities. It is estimated that the incidence of IUGR or SGA infants resulting from these combined factors is between $1.5 \mathrm{c}$; and $3 r_{i}$ of all live births (4). These infants may manifest several clinical problems. including hypoglycemia. and may show abnormal growth palterns during infancy and impaired neurologic development (5. 7-9.12. 15. 25. 32. 37). Investigations concerning the clinical and metabolic problems encountered in infants with IUGR have been limited by the number of appropriate patients available in a given eenter and the techniques which can be utilized to study the underlying pathophysiology and pathobiochemistry. Thus. interest in an animal model for the dysmature infame developed several years ago and led to a method reported by Wigglesworth in 1964 to produce growth retardation in fetal rats (39). The method involses unilateral ligation of uterine vessels and produces a uteroplacental insufficiency state. The progeny from the ligated uterinc horn are characteristically small. defined by convention as 2 SD or $15 \%$ less than the weight of littermates (20). The yickd of dysmature fetuses per pregnancy. however. varies widely and documentattion of optimum operatice approaches and results has not appeared in the litcrature.

Metabolic studie's utilizing the animal model of IUGR have demonstrated that hypoglycemia oceurs in dysmature rat pups at birth and during carly neonatal life. The fall in plasma glucose below normal values is accompanied by decreased liver glyeogen stores in these nemates. as compared to control littermates (6). Observations relative to glycogen production by the livers from IUGR pups have suggested that enzymatic competence exists to carry out the biosynthetic pathway. Indelequate glucose transport from the maternal pool. therefore. may be the main cause for reduced hepatic glycogen levels (26). Prevention of early neonatal hypoglycemia in the animal with IUGR (11) and in the dysmature human infant (3.5) by prenatal glucose administration in large amounts further supports this hypothesis. ()ther methods of influencing neonatal glucose homeostasis. such as administering adrenocorticoids antenally. have been evaluated in normal rat fetuses. but not in those subject 10 intrauterinc growth retardation.

These findings have led to the present study which examines the effect of maternally injected glucocorticoid on the pattern of neonatal hypoglycemia exhibited by rat pups with IUGR. The purposes of this investigation included $(l)$ further characterization of the surgical procedure used in producing animals with IUGR; (2) determination of the incidence and severity of hypo- 
glycemia in the fetally malnourished progeny at birth and under the stress condition of delayed feeding during the first $6 \mathrm{hr}$ of life; (3) assessment of liver glyeogen concentrations in these animals. as compared to plasma glucose levels; and (4) evaluation of the effects of antenatally administered corticoid on plasma glueose and liver glyoogen values in animals at risk for hypoglycemia.

\section{MATIERIALS AND METHODS}

\section{ANIMALS AND SURGICAL PROCIDURIS}

Pregnant Sprague-1)awley rats with accurately timed gestations (within $12 \mathrm{hr}$ ) were utilized in this study. Under ether anesthesia. a low, midline laparotomy was performed on the 17 th to the 19 th day after mating. The uterus was then exposed and the uterine vessels were ligated as described by Wigglesworth (39) near the lower end of one horn using a silk suture. The majority of the surgical procedures designed to produce animals for biochemical studies were carried out on day's 18 and 19 because of more favorable yields of dysmature pups found at these operative times. The vascular supply to the opposite uterine horn was left intact and these animals served as controls. At term (22 days of gestation). delivery by cesarian section wals carricd out under similar operative conditions. Rat pups were weighed immediately after delivery on a Netter PT 200 electronic balance (42). A reduction in weight of more than $15 \%$ compared to the mean of control littermates was considered evidence of fetal growth retardation (20).

\section{EXPERIMENTAL GROUPS OF NIONATES WITH IUGR}

The progeny of 126 pregnant rats comprised the following experimental groups.

Group 1: Newborns at birth. Control and fetally malnourished pups from 25 litters were killed as soon as possible (within 1-5 min) after birth. Blood sampling from severed neck vessels for glucose determination was done before death. The entire liver was then rapidly excised and frozen at $30^{\circ}$ for glyeogen determination.

Group 2: Nutritionally Deprived Newborns. The progeny from 41 litters viclding controls and dysmature pups were maintained without nutritional support for 2-6 hr at an ambient temperature of $32^{\circ}$. Sampling of blood and liver was carried out at either 2,4, or 6 hr of age. The weight of these animats was noted at birth and at the time of death. No attempt was made to follow plasma glucose or liver glycogen values in these animals after 6 hr of life.

Group 3: Glucocorticoid-treated Animals. The progeny from 60 pregnant rats comprised this group. Each dam received an intramuscular injection of 9-(x-fluoroprednisolone acetate (1 $\mathrm{mg} /$ $\mathrm{kg}) 24$ and $48 \mathrm{hr}$ before delivery (43). This steroid is a hydrocortisone analog with potent glucocorticoid activity and was chosen because of its proven competence in previous studies with fetal animals $(19,38)$. The rat pups from these pregnancies were divided as follows. Progeny from 28 litters were killed at birth with sampling of blood and removal of the liver as noted previously. The pups from 32 litters were maintained under conditions of starvation similar to group 2 . Blood sampling was performed and the pups killed at 2-6 hr of age.

\section{PROCISSING OF SAMPLISS AND ANALYTIC PROCEDURES}

Blood, collected in heparin lithium fluoride tubes, was rapidly centrifuged in a Beckman 152 microfuge $(+1)$ and the plasma utilized for duplicate determinations of true glucose. The latter was performed using the specific glucose oxidase method (22) with a Beckman ERA 2001 analyzer (41). Liver samples, frozen for 1-3 weeks before extraction, were weighed and extracted with alcoholic KOH (30\% $\mathrm{KOH}$ in ethanol) as described by Rochrig and Allred (33). This procedure entailed sonication and heating in a boiling water bath for $1 \mathrm{hr}$. After cooling the extract, 1.2 volumes cold $95 \%$ ethanol were added in order to precipi- tate glycogen. Precipitation was carried out overnight at $4^{\circ}$, and the particulate matter collected by centrifugation. Pellets of glyeogen were then washed three times with $70 \%$ " ethanol and hydrolyzed enzymatically by incubation for $10 \mathrm{~min}$ at $55^{\circ}$ with amyloglucosidase (150) units). After centrifugation, the glucose concentration of the sample was measured as described above. The extraction, precipitation, and hydrolysis steps were carried out in the same test tube. Complete hydrolysis of glycogen was shown to result from amyloglucosidase treatment and excellent reproducibility was achicved with this approach.

\section{RESUITS}

\section{EVALUATION OF OPIERATIVE PROCEDURI:}

For animals subjected to surgery at 17,18, or 19 days of gestation, the mean body weight at birth of 184 dysmature pups was $3.46 \pm 0.05 \mathrm{~g}$, whereas that of 3.44 normal control littermates was $5.26 \pm 0.03 \mathrm{~g}(P<0.001)$. Minimal variation in body weights was noted in fetuses delivered from the ligated uterine horn on each operative day.

The yield of fetally malnourished pups varied depending on day of surgery. Operative procedures carried out at 17 days of gestation produced 15 fetuses with IUGR out of a total number of 66, i.e., 23\% on the ligated side, whereas 103 out of 374 $\left(28{ }^{\circ}\right)$ were obtained at 18 days. In contrast, a $399^{\circ} \mathrm{c}$ yield $(66$ dysmature pups produced from a total ligated side number of 167 fetuses) was noted in those animals who underwent uterine artery ligation at a gestational age of 19 days. By the chi square analysis of operative day success rates, significance was noted at the $P<0.005$ level, indicating a trend toward better yiedd at later operative times.

\section{PLASMA GIUCOSE CONCHNTRATIONS}

IUGR and control plasma glucose values obtained during the first $6 \mathrm{hr}$ of neonatal life are presented in Figure 1. At birth, normal controls showed a mean \pm SE plasma glucose value of 6.3 $\pm 2 \mathrm{mg} / \mathrm{dl}$. The incidence of hypoglycemia (plasma glucose $<40$ $\mathrm{mg} / \mathrm{dl}$ ) in these controls was $13 \%$. Plasma glucose values for the group with IUGR at birth were significintly decreased $(P<$ $0 .(0) 1)$ with a mean \pm SE concentration of $43 \pm 2 \mathrm{mg} / \mathrm{dl}$. There was a decline in the plasma glucose level of the dysmature pups during the $2-4-h$ of age period. The mean \pm SE value fell from $39.5 \pm 2 \mathrm{mg} / \mathrm{dl}$ at $0-2 \mathrm{hr}$ of age (0) $20.5 \pm 3 \mathrm{mg} / \mathrm{dl}$. but then returned by 6 hr of age to a level approximating that at birth. The marked decline in plasma glucose values was not found in the control littermates and mean plasma glucose values were

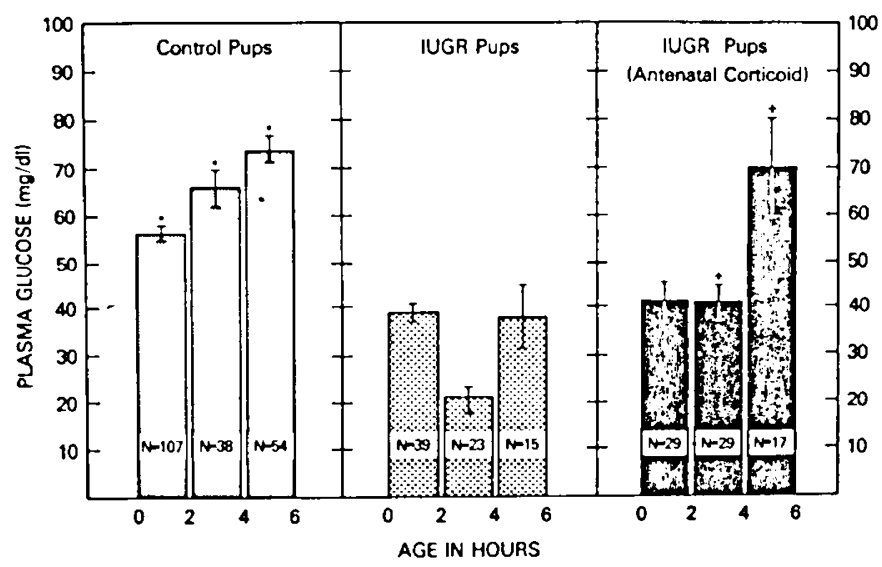

Fig. 1. Mean plasma glucose values of control and intratuterine growth retarded (IUGR) rat pups (nontreated and corticoid-treated groups). Brackets indicatc SE. Asterisks (*) indicate $P<0.001$ compared to the nontreated JUGR group, and plus signs $(+)$ denoted $P=$ 0.005 compared to the nontreated IUGR group. 
maintained in the normoglycemic range throughout early neonatal life $(56.5 \pm 1$ at $0-2 \mathrm{hr} .66 .5 \pm 3$ at $2-4 \mathrm{hr}$. and $74.2 \pm$ $\mathrm{mg} / \mathrm{dl}$ at $4-6 \mathrm{hr})$.

These observations on mean glucose levels were reflected in the incidences of hypoglyemia in the two groups. At birth and through the first $2 \mathrm{hr}$ of neonatal life, $46 \%$ of the pups with IUGR exhibited hypoglycemia. whereas only $18 \%$ of the control littermates manifested low plasma glucose levels. During the 2-4 hr interval. the hypoglycemia rate in animals with IUGR was $91 \%$; the control animals did not show an increase in the percentage of hypoglycemia during that time period. By 4-6 hr of age the hypoglycemic tendency in those with IUGR dropped to $67 \%$ and only $4 \%$ of the control plasma glucose values were less than $40 \mathrm{mg} / \mathrm{dl}$.

\section{LIVER GLYCOGEN (ONIENT ANI) LIVFR WIIGHT}

Table 1 presents the interrelationships between glucose. liver glyeogen, and liver weight noted at birth and during early neonatal life in all the experimental groups.

At birth. the pups with IUGR had a lower mean liver weight as compared to their control littermates $(0.15 \pm 0.06$ versus $0.28 \mathrm{~g} \pm 0.04$. respectively. $P<0.001)$. A weight difference was also found between normogycemic and hypoglycemic dysmature pups $\left(0.17 \pm 0.01\right.$ and $0.12 \pm 0.01 \mathrm{~g}$. respectively. $P^{\prime}<$ $0.001)$.

Comparison of glycogen concentration per g of wet liver weight revealed slightly lower values in the IUGR group $22.2 \pm$ $1.3)$ but no statistically significant difference in the overall mean (control $=25.7 \pm 1.8)$. Total liver glycogen stores at birth. however. Were markedly lower $(P<0.001)$ in dysmature rat pups $(2.96 \pm 0.17 \mathrm{mg})$ compared to control littermates $(7.23 \pm$ $0.43 \mathrm{mg})$.

Figure 2 demonstrates the relationship between mean plasma glucose levels at birth for all animals and total liver glyeogen content. As indicated. a significant correlation $(r=0.64 . p<$ $0.0(01)$ was observed.

In mutritionally deprived animals of $2-4 \mathrm{hr}$ of age. the liver glycogen concentration of the pups with IUGR $(13.6 \pm 1.1 \mathrm{mg} / \mathrm{g}$ wet weight) was also lower $(p<0.0(5)$ than control littermates $(28.3 \pm 3.9)$. This relationship was likewise noted in comparing total hepatic glycogen content. Differences in liver weights between the IUGR and control littermates were again noted at 2-4 hr of age; however. within the group with IUGR. no difference was noted between the normoglycemic and the hypoglyeemic animals.

BFFECT OF ANTINATAL GLUCOCORTICOID ON PLASMA GLUCOSE. LIVER GIYYCOGFN CONTENT, AND LIVIR WIIGHT IN PUPS WTTH IUGR

Plasma gluesese patterns of the pups with IUGR not exposed to exogenous corticoids are compared in Figure 1 to those treated antenatally and also to control pups. The decline in plasma glucose values of dysmature pups during the 2-4-hr period was not present in animals whose dam received glucocorticoid injection 24 and $48 \mathrm{hr}$ before delivery. Further analy sis of the 2-4-hr and 4-6-hr time periods revealed significant differences in plasma glucose values between untreated and treated groups with IUGR. At 4-6 hr. the difference was particularly impressive in that the treated group with IUGR maintained a plasma glucose value $(70.1 \pm 6.92)$ which approximated the control group value and was almost 2 -fold greater than the mean value of $37.5 \pm 7.4 \mathrm{mg} / \mathrm{dl}$ in the nontreated IUGR group $(p<$ $0.005)$. No differences in plasma glucose values were noted in normal control littermates during the same study time periods whether subjected to antenatal corticoids or not.

The average incidence of hypoglyeemial in the two experimental groups of dysmature pups did not differ in the first $2 \mathrm{hr}$ of life (46\% in nontreated animals. $48 \%$ in those exposed to exogenous corticoid). In the subsequent thr. however. the incidenes rates differed. Instead of $91 \%$, an incidence of $55 \%$ was found at 2-4 hr of age. At $6 \mathrm{hr}$. the corticoid-treated group showed an incidence of $18 \%$ as compared to a $67 \%$ figure in nontreated. small-for-gestational age animals.

Although mean glycogen concentration at birth in corticoidtreated IUGR pups was relatively low. a substantial increase was noted in these animals by $2-4$ hr of age (Table 1 ). Thus. mean liver glycogen concentration $(26.9 \pm 1.7)$ in the treated animals at 2-4 hr was significantly greater than the value observed in untreated dysmature pups. During the 2-4-hr age period. total liver glycogen in the corticoid-treated pups with IUGR was also increased significantly compared to the nontreated group. as shown in Table 1. The treated group's mean in fact approximated that of controls at $2-4 \mathrm{hr}$ of age. Liver weights were likewise elevated in the treated group.

\section{DISCUSSION}

Hypoglycemia in human fetuses has been documented in four conditions: fetal growth retardation, pre-eclampsia, accidental hemorrhage, and maternal hypoglycemia (31). Studies in humans obviously are limited, but the animal model of intrauterine

Table 1. Liver weight and glycogen content in newborn rats ${ }^{1}$

\begin{tabular}{|c|c|c|c|}
\hline & Control & IUGR & $\begin{aligned} & \text { IUGR } \\
&+ \text { corticoid } \\
&\end{aligned}$ \\
\hline \multicolumn{4}{|c|}{ Liver weight (g) } \\
\hline At birth & $\begin{array}{c}\left(0.28 \pm 0 .(1) .4^{2}\right. \\
(n=2.5)\end{array}$ & $\begin{aligned} 0.15 & \pm 0.06 \\
(n & =53)\end{aligned}$ & $\begin{array}{c}0.15 \pm 0.04 \\
(n=24)\end{array}$ \\
\hline At $2-4 \mathrm{hr}$ & $\begin{array}{c}0.19 \pm 0 .\left(12^{3}\right. \\
(n=12)\end{array}$ & $\begin{array}{c}0.11 \pm 0.01 \\
(n=40)\end{array}$ & $\begin{array}{l}0.14 \pm 0.01^{3} \\
(n=26)\end{array}$ \\
\hline \multicolumn{4}{|c|}{$\begin{array}{l}\text { Glycogen (mg/g wet } \\
\text { weight) }\end{array}$} \\
\hline At birth & $\begin{array}{r}25.7 \pm 1.8 \\
(n=25)\end{array}$ & $\begin{array}{r}22.2 \pm 1.3 \\
(n=5.3)\end{array}$ & $\begin{array}{c}16.9 \pm 0.79^{4} \\
(n=18)\end{array}$ \\
\hline At $2-4 \mathrm{hr}$ & $\begin{array}{r}28.3 \pm 3.9^{3} \\
(n=12)\end{array}$ & $\begin{aligned} 13.6 & \pm 1.1 \\
(n & =4(1)\end{aligned}$ & $\begin{array}{r}26.9 \pm 1.7^{3} \\
(n=25)\end{array}$ \\
\hline \multicolumn{4}{|c|}{ Glycogen (mg total) } \\
\hline At birth & $\begin{array}{c}7.23 \pm 0.43^{2} \\
(n=25)\end{array}$ & $\begin{array}{c}2.90 \pm 0.17 \\
(n=5.3)\end{array}$ & $\begin{array}{c}2.55 \pm 0.30 \\
(n=18)\end{array}$ \\
\hline At $2-4 \mathrm{hr}$ & $\begin{array}{c}5.26 \pm 0.68^{1} \\
(n=12)\end{array}$ & $\begin{aligned} 1.45 & \pm 0.17 \\
(n & =4(0)\end{aligned}$ & $\begin{array}{c}3.56 \pm 0.32 \% \\
(n=25)\end{array}$ \\
\hline
\end{tabular}

1 IUGR: intrauterine growth retardation. All values represent mean \pm SE; number of animals in parentheses.

${ }^{2} P<0.0(0)$, as compared to the nontreated IUGR group

${ }^{3} P<0.005$, as compared to the nontreated IUGR group

$+P<0.02$, as compared to the nontreated IUGR group.

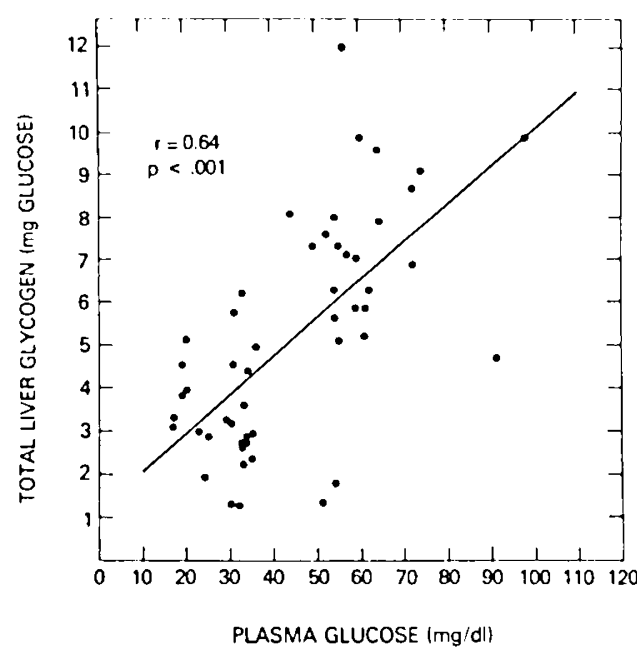

Fig. 2. Correlation between mean plasma glucose concentrations and the total liver glycogen content of control and IUGR pups at birth. 
rowth retardation has enabled investigators to gather data on arly neonatal hypoglycemia and other aspects of carbohydrate netabolism in the small-for-gestational age animal. Work by $\mathrm{Oh}$ ind colleagues (28) led to the hypothesis that impaired placental ransfer of substrate (glucose) to the fetus because of decreased lood flow was the mechanism responsible for low blood glucose alues noted in rat pups with IUGR. Exploration into the cause if neonatal hypoglycemia in the dysmature rat pup was carried ut by Nitzan and Groffman $(26,27)$ whos used in vitro techliques. They demonstrated impared glucose production from abeled alanine in liver slices from these animals and suggested hat a delay in postnatal development of hepatic gluconeogenesis night contribute to the hypoglycemia associated with fetal matutrition. An examination of hepatic enzymes by Chanez and coworkers (6), however, failed to reveal any significant abnornalities in the various enzymes involved in gluconeogenesis. On he other hand, data suggesting a decrease in phosphoenolpyrurate carboxykinase (PEPCK) activity, a key step in glucogeoneis, was gathered by Philippidis and Ballard (30). A relative leficiency of this enzyme in fetal liver was observed, and it was sostulated that a defect in the development of PEPCK activity sxisted in the dysmature newborn animal.

It was the purpose of our investigation to concentrate on the first $6 \mathrm{hr}$ of neonatal life in the dysmature rat and to determine the incidence and severity of hypoglyeemia and whether prenatally administered glucocorticoid could alter the pattern of hypoglycemia in intrauterine growth retardation. Placental transfer of cortisol analogs similar to the agent used in this study has been demonstrated by Ballard et al. (2) and Barrett et al. (3).

Data from this study indicate that the 2-4 hr postnatal period is a critical time for the development of hypoglycemia in that $91 \%$ of growth-retarded newborns became hypoglycemic during that time. The hypoglycemic tendency appeared immediately after birth when $39 c_{0}^{\circ}$ of the animals with IUGR were noted to have plasma glucose values less than $40 \mathrm{mg} / \mathrm{dl}$. When compared to control littermates at birth, the dysmature pups had similar mean values for glycogen concentration per g liver, but lower total liver weight and total liver glycogen content. A correlation was identified between mean plasma glucose levels at birth and total liver glycogen content. During the $2-4$-hr neonatal period, significant differences continued to be present between control and fetally malnourished pups, including values for plasma glucose, glycogen, and total liver weight.

Protection from the trend toward low plasma glucose values in the dysmature rat pup was demonstrated in the group of experimental animals who were exposed $48 \mathrm{hr}$ before birth to maternally administered glucocorticoid. The lowered incidence of hypoglycemia in the corticoid-treated group of pups with IUGR during the 2-4-hr postnatal period was accompanied by higher mean plasma glucose concentrations compared to those of nontreated IUGR animals. The difference in mean plasma glucose in these two groups extended to the 4-6-hr neonatal period. However, no significant effect of antenatal corticoids was noted in the glucose pattern of controls during the same time period. At birth, hepatic glycogen concentration in corticoid-exposed controls wats also equivalent to values in nontreated controls. The corticoid-treated, dysmature group exhibited a marked increase in total liver weight and glycogen concentration per wet liver weight; this was reflected in the markedly greater hepatic glyeogen stores in the treated animals. Thus, it would appear that antenatally administered glucocorticoid influences the development of neonatal hypoglycemia in the fetally malnourished rat and that the major effect is not at birth, but during the 2-4-hr period of neonatal life.

A number of possibilities exist to explain the mechanism of glucocorticoid action on neonatal glucose homeostasis. Control of glucose metabolism by adjustments in enzyme activities is a well established phenomenon (13). Developmental patterns of liver enzymes involved in glucose metabolism have been studied by a number of investigators $(10,13,16,36,40)$; results of this work have been reviewed in detail by Greengard (13). It has been shown that injection of thyroxine and cortisol enhances the development of enzyme activities normally present in the late fetal period. Among these are glycogen synthetase, which appears in a more active form in fetuses given steroids (14), and tyrosine aminotransferase (17). In studying the effect of glucocorticoids on key hepatic enzymes of gluconeogenesis, Yeung and associates (40) reported a slight depression of glucose-6phosphatase activity and a $50 \%$ depression of hexose diphosphatase in the fetal rat liver. In further investigations, it wats shown that pyruvate kinase and aspartate aminotransferase activities in fetal rat liver were both depressed by treatment, whereas phosphofructokinase activity was elevated. These investigators concluded that glucocorticoids did not initiate the synthesis of gluconeogenic enzymes and that steroids might play a role in control mechanisms for regulation of enzyme activities once synthesis was initiated (14).

Other investigators have evaluated the activity of PEPCK, an enzyme which catalyzes the transformation of oxaloacetate into phosphoenolpyruvate and which plays an important role in gluconeogenesis. It has been shown that glucocorticoid administration causes an increase in the activity of this enzyme. Presumably, this could enhance the capacity of the gluconeogenic pathway (29).

Clinical studies in small-for-gestational age infants have examined glucose responses and plasma amino acid patterns (21) after intravenously injected alanine, and compared the changes with those of full term infants $(23,24)$. Marked hyperaminoacidemia was noted in SGA infants, particularly affecting alanine, proline, valine, and glycine. It has therefore been proposed by Mestyan et al. (23, 24) that factors responsible for the provision of substrates for glucose synthesis may be present in the small-forgestational age infant, but that insufficient hepatic gluconeogenic enzymes contribute to impaired glucose homeostasis.

Animal correlates utilizing the Wigglesworth model of IUGR indicate a somewhat similar change in blood amino acid patterns during the first 3 day's of life $(1,34)$. The ratio of nonessential to essential amino acids in the rat pup with IUGR is increased over that of the control animal. Between 3 and 5 days after birth, all amino acid changes seem to disappear except for high levels of alanine in dysmature progency. It is perhaps this relative inability to produce glueose from alanine that may explain the persistent pattern of hypoglycemia in some of the newborns with IUGR. If this is the case, then one might postulate that glueocorticoids act favorably on glucose homeostasis by increasing amino acid transport and bringing about more effective utilization of gluconeogenic substrate. Further investigations are needed, however, regarding the precise mechanism of action of steroids in protecting the rat pup with IUGR from neonatal hypoglyeemia.

\section{CONCLUSION}

An animal model (rat) of the IUGR state associated with uteroplacental insufficiency was utilized to evaluate the effect of maternally administered glucocorticoid on the hypoglycemic tendency of growtb-retarded progeny. Through the first $2 \mathrm{hr}$ of neonatal life. $46 \%$ of the pups with IUGR exhibited hypoglycemia, whereas only $18 \%$ of control pups manifested this state. The incidence of hypoglycemia in animals with IUGR increased to $91 \%$ during the $2-4-h r$ time interval, whereas control pups maintained their low incidence with the value eventually falling to $4 \%$ at 4-6 hr of age. Concentration of plasma glucose at birth of individual control and IUGR progeny were found to correlate significantly with total liver glycogen content. Total hepatic glycogen stores in the fetally malnourished animals were markedly lower than those of controls. With prenatal glucocorticoid administration, there was no decline in the plasma glucose values of pups with IUGR and at $4-6$ hr of age, the dysmature pups attained mean plasma glucose concentrations approximating those of nontreated control animals. Liver glycogen content in the treated pups with IUGR also showed significantly higher values than the nontreated IUGR progeny. 


\section{REFI:RI:NCES ANI) NOTES}

1. Aikawa, T., Matsutaka, H., Yamamota, H., Okuda, T., Nhikawa, E., Kawano, T., and Metsumura, E.: Gluconeogenesis and amino acid metabolism. I1. Interorganal relations and roles of glutamine and alanine in the amino acid metabolism of fasted rats. J. Biochem., 74: 1003 (1973).

2. Ballard, P. L., Granberg, P., and Ballard, R.: Glucocorticoid levels in maternal and cord serum after prenatal betamethasone therapy to prevent the respiratory distress syndrome. J. Clin. Invest., 56: 1548 (1975)

3. Barrett, C. T., Sevanian, A., Lavin, N., and Kaplan, S. A.: Role of ademosine 3', 5'-monophosphate in maturation of fetal lungs. Pediat. Res., 10: 621 (1976).

4. Battaglia, F. C.: Intrauterine growth retardation. Amer. J. Obstet. Gynecol., 106: $110.3(1970)$

5. Brown, R. J. K. and Wallis, P. G.: Hypoglycemia in the newborn infant. Lancet, $i: 1278(1963)$

6. Chanez, C., Tordet-Cardiroit, C. and Roux, J. M.: Studies on experimental hypotrophy in the rat. II. Development of some liver enzymes of gluconeor genesis. Biol. Neonate, 18: 58 (1971).

7. Coates, J. R.; Neonatal hypoglycemia. Med. J. Aust., 1: 11 (1974).

8. Cornblath, M., and Reisner, $S$. A. Blood glucose in the neonate and its clinical significance, New Engl. J. Med., 273: 378 (1965).

9. de Leeuw, R. and Vries, 1. J.: Hypoglycemia in small-for-dates newbom infants. Pediatrics, 58: 18 (1976).

10. Devos, P. and Hers, H.: Glycogen metabolism in the liver of the foetal rat. Biochem. J., $1+0: 331$ (1974).

11. Exton, J. H., Friedmann, N., Wong, E. H., Brineaux, J. P., Corbin, J. D. and Park, C. R.: Interaction of glucocorticoids with glucagon and epinephrine in the control of glueoneogenesis and glycogenolysis in liver and of lipolysis in adipose tissue. J. Biol. Chem., 247: 3579 (1972).

12. Fluge, G.: Neurological findings at follow-up in neonatal hypoglyeemia. Acta Patediat. Scand. 64: 629 (1975)

13. Greengard, O.: Enzymic and morphological differentiation of rat liver. In: J. Dancis and J. C. Hwang: Perinatal Pharmacology: Problems and Priorities, p. 15 (Raven Press, New York, 1974).

14. Greengard, O., and Dewey, H. K. The premature deposition or lysis of glycogen in livers of fetal rats injected with hydrocortisone or glucagon. Develop. Biol., 21: 452 (1970).

15. Gutherlet, R. L. and Comblath, M.: Neonatal hypoglycemia revisited, 1975. Pediatrics, 58: 10 (1976)

16. Hanson, R. W., and Garber, A. J.: Phosphoetwolpyrusate carboxykinase. 1. Its role in gluconeogenesis. Amer. J. Clin. Nutr. 25: 1010 (1972).

17. Holt, P. G., and Oliver, I. T.: Factors affecting the premature induction of yrosine aminotransferase in foctal rat liver. Biochem. J., lOS: 333 (1968).

18. Kletzien, R. F., Pariza, M. W., Becker, J. F. and Potter, V. R.: A "permic sive" effect of dexamethasone on the glucagen induction of amino acid transport in cultured hepatocyles. Nature, 250: 46 (1975)

19. Kotas, R. V., Fletcher, B. D., Torday, J. and Avery, M. B.: Evidence for independent regulators of organ maturation in fetal rabbits. Pediatrics, 4.5: 57 (1971).

20. Kous, J. M., Tordet-Caridroit, C. and Chane\%, C.: Studies on experimental hypotrophy in the rat. 1 . Chemical composition of the total body and some organs in the rat foetus. Biol. Neonate, 15: $342(1970)$.

21. Lindbald, B. S.: The venous plasma free amino acid levels during the first hours of life, 1. After normal and short gestation complicated by hypertension. With special reference of "small for dates" syndrome. Acta Paediat. Scand.. 59: 13, (1970).
22. Marks, V.: An improved glucose-oxidase method for determining bleod.c.s.f and urine glucose levels. Clin Chim Acta, 4: 395 (1959).

23. Mestyan, J., Schulta, K., and Horvath, M.: Comparative glycemic responses to alanine in normal term and small for gestational age infants. J. Pediat., 85: $276(1974)$

24. Mestyan, J., Soltesz, G., Schultz, K and Horvath, M.: Hyperaminoacidemia due to the accumulation of gluconeogenic amino acid precursors in hypoglycemic small for gestational age infants. J. Pediat., 87: $4(1)$ (1975).

25. Neligan, G. A., Robson, E., and Watson, J.: Hypoglycemia in the newhorn; a sequel of intratuerine malnutrition. Lancet $i: 1282(196,3)$

26. Nitzan, M. and Groffman, H.: Glucose metabolism in experimental intrauterine growth retardation: In vitro studies with liver and brain slices. Biol. Neonate, 17: $420(1971)$.

27. Nitzan, M., and Groffman, H.: Hepatic gluconeogenesis and lipogenesis in experimental intrauterine growth retardation in the rat. Amer. J. Obstet. Gynecol., 109: 623 (1971)

28. Oh, W., D'Amodio, M. D., Yap, L. L. and Hohenauer, L.: Carbohydrate metabolism in experimental intrauterine growth retardation in rats. Amer. J. Obstet. Gynecol. 108: 415 (1970).

29. Peret, J. and Chanez, 11 .: Influence of diet, cortisol and insulin on the activity of pyruvate carboxylase and phosphoenolpyruvate carboxy hinase in the rat liver. J. Nutr., 106: $103(1976)$.

30. Philippidis, H. and Ballard, F. J.: The development of gluconeogenesis in rat liver, experiments in vivo. Biochem J., 113:651 (1969).

31. Phillips, L., Lumley, J., Paterson. P. and Wood, C.: Fetal hypoglycemia Amer. J. Obstet. Gynecol., 102: 371 (1968).

32. Pildes, R. S., Cornblath, M., Warren, I., Page-EI, E., di Menza, S., Merritt, D. M. and Peeva, A.: A prospective controlled study of neonatal hypoglycemia. Pediatrics, 54: 5 (1974).

33. Rochrig. K. L. and Allred, J. B.: Direct enzymatic procedure for the determination of liver glycogen. Anal. Biochem., 58: 414 (1974).

34. Roux, J. M. and Jahcan, T.: Plasma level of amino-acids in the developing young rat after intrau-uterine growth retardation. Life Sci., 14: 1101 (1974).

35. Sabata, V., Znamenacek, K., Pribylova, H. and Melichar, V.: The effect of glucose in the prenatal treatment of small-for-date fetuses. Biol. Neonate. 22: 78 (1973).

36. Schwartz, A. L., and Rall, T. W.: Hormonal regulation of glycogen metabolism in neonatal rat liver. Biochem. J., 134: 985 (1973).

37. Shelley, H. J. and Neligan, G. A.: Neonatal hypoglycemia. Brit. Med. Bull., 23: $34(1966)$.

38. Weber, G.: Steroid action: Phenotypic evidence for reprogramming of gene expression. In: C. A. Villee, D. B. Villee, and J. Zuckerman: Respiratury Distress Syndrome, p. 237 (Academic Press. New York, 1973).

39. Wigglesworth. J. S.: Experimental growth retardation in the loctal rat. J. Path. Bacteriol., $88: 1(1964)$.

40. Yeung, D., Stanley, R. S. and Oliver, I. T.: Development of gluconeogenesis in neonatal rat liver: Effect of triamcinolone. Biochem. J., 105: 1219 $(1967)$.

41. Beckman Instrument Corporation. Silver Spring, Md.

42. Mettler Instrument Corporation, Princeton, N. J

43. The Upjohn Company, Kalamazon, Nich.

44. Requests for reprints should be addressed to: R. L. Manniello, M.D. National Institutes of Health Bldg. 10. Room 13N260. Bethesda, Md $2001+($ USA)

45. Received for publication September 14, 1976 .

46. Accepted for publication November $18,1976$. 